\title{
ADAPTIVE LOGISTICS MANAGEMENT AND OPTIMIZATION THROUGH ARTIFICIAL INTELLIGENCE
}

\begin{abstract}
Adaptive logistics management can be reached using artificial intelligence and optimization processes. The paper deals with adaptive logistics management in order to allow direct communication between logistics management systems and logistics facilities, machines, robots and mobile robot system using AI and adaptive behavior in logistics processes. In addition, the paper discusses development trends in adaptive logistics processes and new features such as holonic systems of autonomic logistics management.
\end{abstract}

Keywords: Adaptive logistics, advanced industrial engineering, intelligent logistics management, machinery industry.

\section{Introduction}

One aspect of the development of new production systems is ever-growing requirements for adaptability. Logistic systems have to become more adaptive as well. We see the growing trend of employing the concept of Factories of the Future (FoF) and Intelligent Manufacturing Systems (IMS), which are being supported in Slovakia by the Smart Industry, a movement that is gaining momentum under the auspices of the Ministry of Economy of the Slovak Republic and the German industry program Industry 4.0. The topic of smart logistics systems (Smart Logistics) is becoming very popular.

Corporate logistics system is a complex, holonic system. It is formed by separate elements, holons, which are autonomous, able to communicate with each other, collect data by means of sensors, learn, make decisions based on the current production conditions, optimize and predict the future trajectories and solve management tasks at their level. The research in the field of logistics also focuses on cognitive logistics. The aim of all these changes is to give

logistics systems the ability to easily adapt to the changing conditions of the production process. In order for the field of logistics to go through such a significant transformation it has to change all its elements so that they are able to communicate with each other and perform their tasks together. The following topics are becoming more and more popular: identification technology (RFID) smart pallets, intelligent mobile robots, cooperative robots, automatic sorting and storage systems, multiagent management systems, machine communication (M2M -
Machine to Machine), new visualization production systems, new systems for human-machine cooperation (HMI - Human Machine Interface), Internet of Things, cloud computing and so on. In order to implement these changes and prevent utter chaos in the production environment these methods require standardized solutions.

This paper is divided into 6 main chapters that demonstrate concepts contributing to the development of adaptive logistics management in order to enhance adaptability in unstable environments and apply intelligent and adaptive behavior in logistics processes. Chapter 2 deals with literature survey that will be used for the analysis of new knowledge in adaptive logistics. Chapter 3 outlines a detailed explanation of the issue. Chapter 4 outlines design methods regarding adaptive logistics management using holonic approach. Chapter 5 features a case study of adaptive logistics thanks to which we can draw up a schedule for outlining maximum power of logistics or the maximum power of the assembly line. Chapter 6 outlines a short summary and a proposal for future research.

\section{Literature survey}

The first prerequisite of adaptability is a functional modular logistics system, which is often a precondition for a quick reconfigurability of any logistics system. Modularity is a precondition for reconfigurability, however, a logistics system can be reconfigurable even though it lacks modularity conditions.

\footnotetext{
* ${ }^{1}$ Branislav Micieta, ${ }^{2}$ Jolanta Staszewska, ${ }^{1}$ Vladimira Binasova, ${ }^{1}$ Jozef Hercko

${ }^{1}$ Department of Industrial Engineering, Faculty of Mechanical Engineering, University of Zilina, Slovakia

${ }^{2}$ Department of e-Business and e-Economy, Faculty of Economics and Management, Opole University of Technology, Opole, Poland

E-mail: vladimira.binasova@fstroj.uniza.sk
} 
The individual elements of the logistics system must be designed in a way they can cooperate and communicate without any problems - they have to be able to cooperate from a technical (hardware, mechanical, energy), as well as from a software (control) point of view. The resulting modularity of logistics elements will thus allow rapid scalability of and adaptability to the whole logistics system.

Adaptive logistics systems will use a wide range of advanced technologies. Individual elements of the logistics system will be equipped with small, powerful computers, the so-called embedded intelligence which will thus extend their functionality and autonomy. Ability to communicate with each other will be supported by a new generation of wireless sensor networks, utilizing the intelligent information infrastructure, technologies related to the Internet of things and cloud services.

Among the new features of the adaptive logistics are the following: holonic systems of autonomous logistics management in real-time, modular structure supporting reconfigurability (plug and produce), mechatronic systems and incorporated intelligence, sensors and systems used for internal actions, sensor technology for the surroundings of the logistics system (systems for external actions), decision support systems using simulations and emulations.

The time needed for the development of new technology increases a time gap in product development. The first person who described the characteristics of reconfigurable manufacturing systems (RMS) was Professor Y. Koren from the University of Michigan [1].

Logistics systems are made up of hardware, software and peopleware elements. The importance of peopleware elements is gradually decreasing since they are being replaced by machines, robots and computers [2]. The digitization of the 21st century has dramatically increased the importance of software. The dynamics of digitization, the huge growth of computing power, miniaturization, software development services together with the use of artificial intelligence, Internet of Things and cloud enabled the implementation of intelligence directly into logistical facilities (this is known as the embedded intelligence) [3]. Huge amount of data on internal and external factors arising as a result of the massive use of sensors enables the processing of new technologies for Big Data [4]. Information and knowledge gained from data brings about a new era of knowledge engineering where knowledge is not produced exclusively by humans, but machines too (as a result of the processing of computer data). Software and software services and their development have become a prerequisite for further development of logistics.

The relationship between capacity and functionality change in the reconfigurable manufacturing systems is shown in Fig. 1.

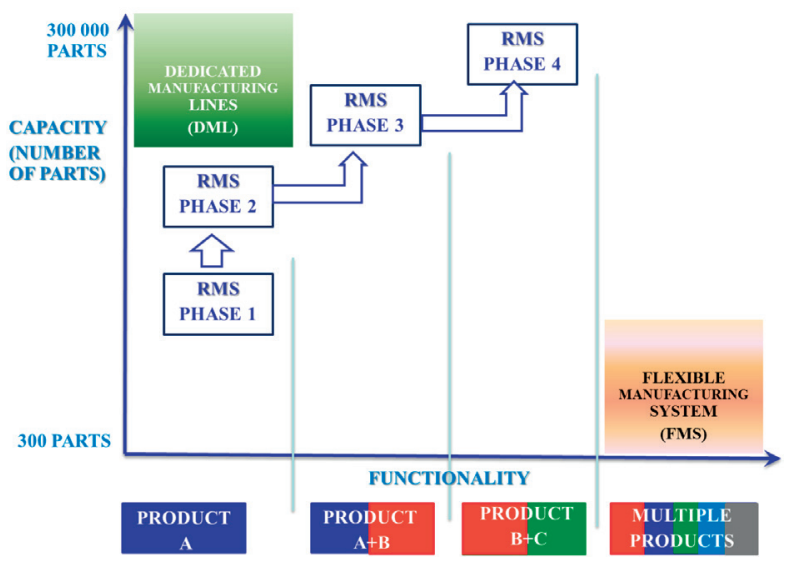

Fig. 1 Capacity and functionality change in the reconfigurable manufacturing system [1]

\section{Problem definition}

The concept of intelligent logistics management (Fig. 2) is based on 14 solutions that are interconnected and make one "logistics network". Currently, not all of these solutions are fully integrated and connected to IT infrastructure of enterprises. In the future this concept will face big challenges like Internet of Things [5], Internet of Service and Smart Factory [6].

This concept of intelligent logistics was made using the method of Value Stream Mapping. Development of an enterprise with a focus on the implementation of the concept of Industry 4.0 is based on the concept of lean enterprise as well as

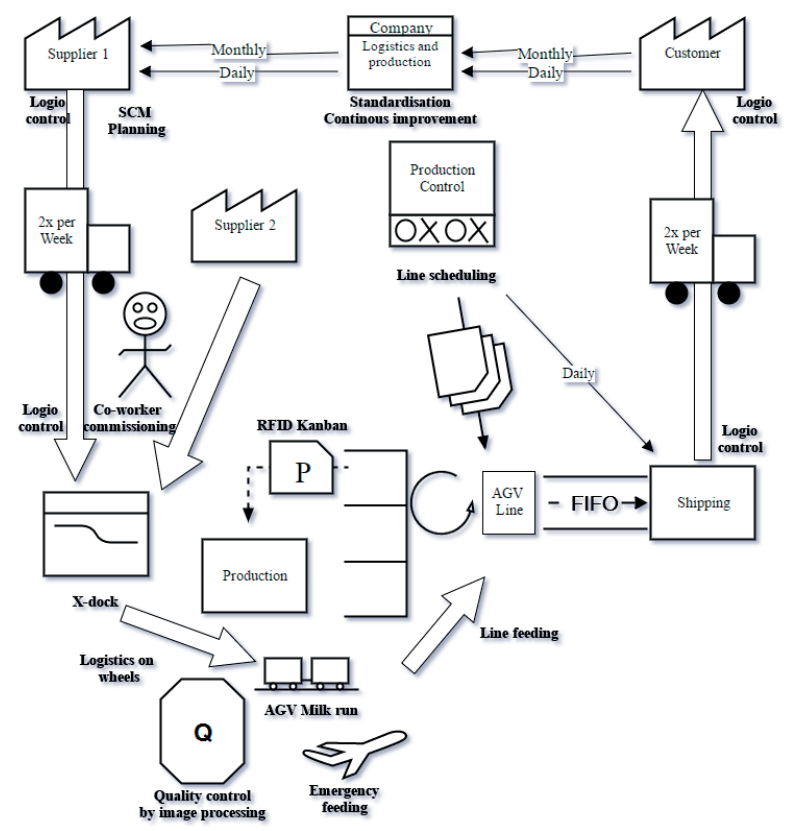

Fig. 2 Concept of intelligent logistics management 
the elimination of waste. The concept of lean enterprise is almost in all instances linked with low cost automation. As the time goes, complex automated systems and ICT are gradually becoming automated, too. Many of them are essential (security gateways, software for administrative and technical staff, etc.) for the enterprise. It should be noted that automation should be integrated into systems that are already cleaned of waste [7] Otherwise, an enterprise will automate the creation of waste and costs, thus reducing its competitive advantage.

\section{Design method}

A new logistics concept CEIT MRS 2020 uses the holonic principle. All information necessary for the management is divided by the management system between three main categories: form of transport (pallets, boxes), means of transport (trucks, MRSmobile robotic systems, conveyors, services (software, software as a service). The growing complexity of relationships in the logistics system and the need to make quick decisions at the local level appears to be best handled with use of agents [8]. Holonic concept of internal logistics management concept is being developed in collaboration with CEIT and UVP University of Zilina under the ZIMS (Zilina Intelligent Manufacturing Systems). Its structure is shown in Fig. 3. More detailed information on ZIMS holonic concept was published in [6].

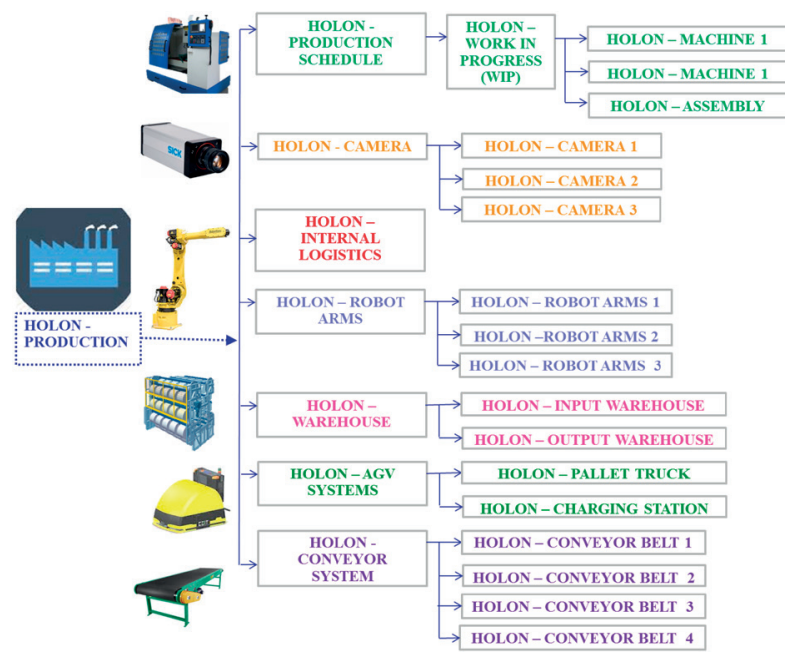

Fig. 3 Holonic production structure

\section{Case study}

Production process can be simplistically described as a sequence of steps (processes) between the order receipt and the receipt of payment for the product. Production process is a summary of financial, information and material flows [9 and 10]. In most cases financial and information flows are more complex and time-consuming. Furthermore, we will address in particular the information flow with regard to scheduling and associated material flows. An important task here is optimization of planning and scheduling of the production system [11 and 12] because these processes can accelerate cash flow and return on capital in the enterprise (time and supply reliability, capacity utilization and the level of stocks). Production should be scheduled in a way it meets customer requirements [13].

The methodology for determining the optimal sequence according to selected criteria deals with the determination of a uniform schedule in order to minimize inventory and production time. However, it does not directly support the objective of load balancing (operators, equipment) on the line and in logistics, minimizing time needed for sorting, or determining the weight of above-mentioned criteria or the mix according to all the rules. The following Fig. 4 clarifies the issue.

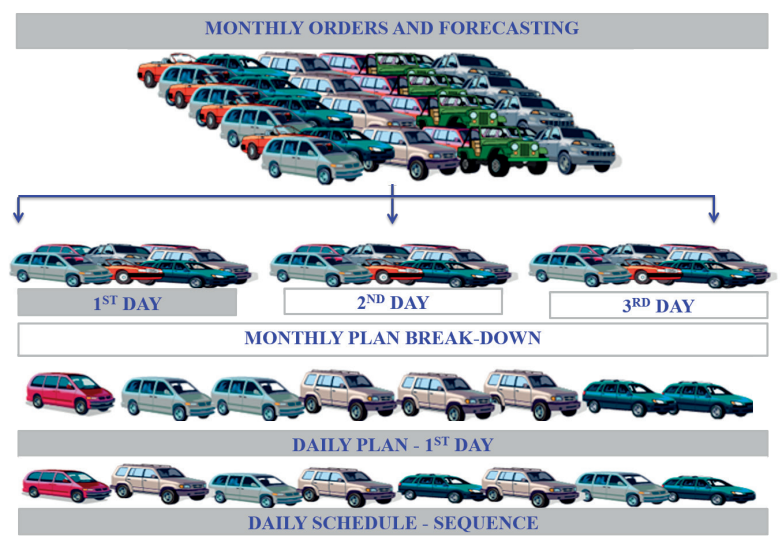

Fig. 4 Determining the sequence of products in order to minimize inventory, work in progress and production time (Model Sequencing Method)

In order to reach the maximum output of the line, the sequence coefficients can help us determine the best sequence for the production of products (together with operation times). Sequence coefficients are calculated for each operation and multiplied by the priority. The following Table 1 outlines the sequence coefficients for one production line.

The following Fig. 5 compares two types of schedules. One rule is designed to maximize the capacity and the second rule to minimize inventory on the assembly line. The rule designed to maximize the capacity had been drawn up on the principles of the methodology minimizing inventory, but still, this methodology has not been published yet.

Fig. 5 shows that in the case of using the concept of minimizing inventory the production slows down, thereby causing a lower performance of the production line. 
Sequence coefficients for the whole production line

Table 1

\begin{tabular}{|c|c|c|c|c|c|c|c|c|c|}
\hline \multirow[b]{3}{*}{ Product } & \multirow{2}{*}{\multicolumn{2}{|c|}{$\begin{array}{l}\text { Operation "a" } \\
\text { Priority: 90\% }\end{array}$}} & \multirow{2}{*}{\multicolumn{2}{|c|}{$\begin{array}{l}\text { Operation "b" } \\
\text { Priority: } 3.3 \%\end{array}$}} & \multirow{2}{*}{\multicolumn{2}{|c|}{$\begin{array}{l}\text { Operation "c" } \\
\text { Priority: } 3.3 \%\end{array}$}} & \multirow{2}{*}{\multicolumn{2}{|c|}{$\begin{array}{l}\text { Operation "d" } \\
\text { Priority: } 3.3 \%\end{array}$}} & \multirow{3}{*}{$\begin{array}{l}\text { Order coeff } \\
\text { for line }\end{array}$} \\
\hline & & & & & & & & & \\
\hline & Time & Coeff. & Time & Coeff. & Time & Coeff. & Time & Coeff. & \\
\hline A & 4 & $8.78 \%$ & 3 & $0.32 \%$ & 2.5 & $0.32 \%$ & 3 & $0.32 \%$ & $9.74 \%$ \\
\hline B & 2 & $17.14 \%$ & 1 & $0.55 \%$ & 3 & $0.62 \%$ & 2 & $0.60 \%$ & $18.91 \%$ \\
\hline A & 4 & $17.56 \%$ & 3 & $0.64 \%$ & 2.5 & $0.63 \%$ & 3 & $0.64 \%$ & $19.47 \%$ \\
\hline $\mathrm{C}$ & 1 & $18.00 \%$ & 4 & $0.78 \%$ & 3 & $0.76 \%$ & 2 & $0.73 \%$ & $20.27 \%$ \\
\hline A & 4 & $26.34 \%$ & 3 & $0.96 \%$ & 2.5 & $0.95 \%$ & 3 & $0.96 \%$ & $29.21 \%$ \\
\hline $\mathrm{D}$ & 2.5 & $26.47 \%$ & 2 & $0.94 \%$ & 2.5 & $0.97 \%$ & 4 & $1.02 \%$ & $29.40 \%$ \\
\hline B & 2 & $34.29 \%$ & 1 & $1.10 \%$ & 3 & $1.24 \%$ & 2 & $1.20 \%$ & $37.82 \%$ \\
\hline A & 4 & $35.12 \%$ & 3 & $1.28 \%$ & 2.5 & $1.27 \%$ & 3 & $1.28 \%$ & $38.95 \%$ \\
\hline $\mathrm{C}$ & 1 & $36.00 \%$ & 4 & $1.55 \%$ & 3 & $1.52 \%$ & 2 & $1.47 \%$ & $40.54 \%$ \\
\hline A & 4 & $43.90 \%$ & 3 & $1.60 \%$ & 2.5 & $1.59 \%$ & 3 & $1.60 \%$ & $48.68 \%$ \\
\hline B & 2 & $51.43 \%$ & 1 & $1.65 \%$ & 3 & $1.86 \%$ & 2 & $1.80 \%$ & $56.73 \%$ \\
\hline A & 4 & $52.68 \%$ & 3 & $1.92 \%$ & 2.5 & $1.90 \%$ & 3 & $1.92 \%$ & $58.42 \%$ \\
\hline D & 2.5 & $52.94 \%$ & 2 & $1.89 \%$ & 2.5 & $1.94 \%$ & 4 & $2.03 \%$ & $58.80 \%$ \\
\hline $\mathrm{C}$ & 1 & $54.00 \%$ & 4 & $2.33 \%$ & 3 & $2.28 \%$ & 2 & $2.20 \%$ & $60.81 \%$ \\
\hline A & 4 & $61.46 \%$ & 3 & $2.24 \%$ & 2.5 & $2.22 \%$ & 3 & $2.24 \%$ & $68.16 \%$ \\
\hline B & 2 & $68.57 \%$ & 1 & $2.20 \%$ & 3 & $2.48 \%$ & 2 & $2.40 \%$ & $75.65 \%$ \\
\hline A & 4 & $70.24 \%$ & 3 & $2.55 \%$ & 2.5 & $2.54 \%$ & 3 & $2.55 \%$ & $77.89 \%$ \\
\hline $\mathrm{C}$ & 1 & $72.00 \%$ & 4 & $3.11 \%$ & 3 & $3.05 \%$ & 2 & $2.93 \%$ & $81.09 \%$ \\
\hline A & 4 & $79.02 \%$ & 3 & $2.87 \%$ & 2.5 & $2.86 \%$ & 3 & $2.87 \%$ & $87.63 \%$ \\
\hline D & 2.5 & $79.41 \%$ & 2 & $2.83 \%$ & 2.5 & $2.91 \%$ & 4 & $3.05 \%$ & $88.20 \%$ \\
\hline B & 2 & $85.71 \%$ & 1 & $2.75 \%$ & 3 & $3.09 \%$ & 2 & $3.00 \%$ & $94.56 \%$ \\
\hline A & 4 & $85.71 \%$ & 3 & $3.19 \%$ & 2.5 & $3.17 \%$ & 3 & $3.19 \%$ & $95.27 \%$ \\
\hline A & 4 & $8.78 \%$ & 3 & $0.32 \%$ & 2.5 & $0.32 \%$ & 3 & $0.32 \%$ & $9.74 \%$ \\
\hline B & 2 & $17.14 \%$ & 1 & $0.55 \%$ & 3 & $0.62 \%$ & 2 & $0.60 \%$ & $18.91 \%$ \\
\hline
\end{tabular}

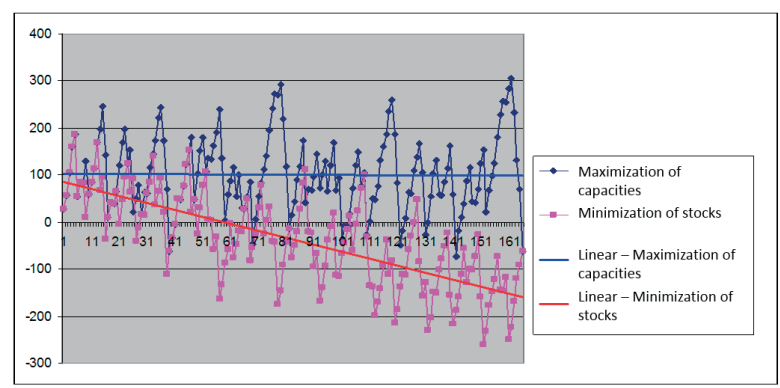

Fig. 5 Graphical comparison of time delays in case of the two types of schedules

The difference in the second case is $1.75 \%$, which would mean an increase by around 8.4 cars per shift (automotive industry).

\section{Conclusion}

The given model pays attention to the methodology of uniform scheduling of products for mass production. It should be noted that using the method of scheduling it is possible to create a schedule aimed at maximizing the power of logistics or power of the assembly line.

Logistics systems, in response to the demands of the production environment, have long been experiencing significant changes leading to the decentralization and individualization. In order for decentralized and individualized elements to cooperate with each other, they must be designed as holonic systems. Such systems will use mobile sensor networks to communicate with each other. They will allow direct communication between logistics management systems and logistics facilities, machines, robots and mobile robot systems (MRS) without the need for human intervention. Each device will behave completely independently, will be able to learn and decide independently. 
This type of logistics can be labeled as smart logistics. Such changes require efficient production environment. Production processes now use the concept of minimum stocks, short interim periods and high utilization of capital assets and resources. These concepts are now a standard. The future requirements for logistics include new features such as high level of autonomous adaptation, self-organization, reconfigurability.

Logistics must also respond to significant changes which take place in production processes - a completely new concept of the production flow. Under this concept the product itself will become a carrier of information about material flow in the production process. The product will serve as an individual entity that will organize its way of production; it will reserve the necessary resource capacity and perform quality control.
This will require entirely new forms of inter-operation transport and handling that will be able to quickly change their capacities and functionality (they can be quickly reconfigured). Examples include mobile robotic systems with integrated cooperative robots capable of serving as production assistants, and, like a human, help out in various workplaces and work together on a variety of logistics actions and different operations. Such changes are brought about the notion of controlled chaos.

\section{Acknowledgements}

This paper was supported by research project VEGA $1 / 0559 / 15$.

\section{References}

[1] KOREN, Y., SHPITALNI, M.: Design of Reconfigurable Manufacturing Systems. J. of Manufacturing Systems, 2011, vol. 29, No. 4, 130-141, ISSN 0278-6125.

[2] KRAJCOVIC, M. et al.: Intelligent Manufacturing Systems in Concept of Digital Factory. Communications - Scientific Letters of the University of Zilina, vol. 15, No. 2, 2013, 77-87, ISSN 1335-4205.

[3] HLAVNA, V., ISTENIK, R.: Possibilities of Solution of an Automobile Designing and Operation in Relation to the Environment. Communications - Scientific Letters of the University of Zilina, vol. 5, No. 1, 2003,16-25, ISSN 1335-4205.

[4] KOHAR, R., HRCEK, S.: Dynamic Analysis of a Rolling Bearing Cage with Respect to the Elastic Properties of the Cage for the Axial and Radial Load Cases. Communications - Scientific Letters of the University of Zilina, vol. 16, No. 3A, 2014, 74-81, ISSN 1335 4205.

[5] GREGOR, M., MEDVECKY, S.: Zilina University Concept of Digital Factory. Communications - Scientific Letters of the University of Zilina, vol. 10, No. 2, 2008, 60-66, ISSN 1335-4205.

[6] GREGOR, M.: CEIT MRS 2020. CEIT Mobile Robotics. R\&D Routing Till 2020 (in Slovak), CEIT, p. 66, CEIT-S010-09-2015.

[7] VYATKIN, V.: Function Blocks for Embedded and Distributed Control Systems Design, New Zealand: ISA, 2011, ISBN 978-1-93600793-6.

[8] BOTTI, V., GIRET, A.: A Multi-agent Methodology for Holonic Manufacturing Systems, London, 2008, ISBN 978-1-84800-309-5.

[9] MICIETOVA, A., CILliKOVA, M., SALAJ, J.: Influence of Some Selected Factors on Surface Quality when Cutting by Plasma and Laser Beam, J. of Machine Manufacturing: Design and Manufacturing, vol. 49, No. E3-E5, 2009, 104-106, ISSN 0016-8580.

[10] BOTTI, V., GIRET, A.: A Multi-agent Methodology for Holonic Manufacturing Systems, London, 2008, ISBN 978-1-84800-309-5.

[11] BUBENIK, P., HORAK, F. HANCINSKY, V.: Acquiring Knowledge Needed for Pull Production System Design through Data Mining Methods. Communications - Scientific Letters of the University of Zilina, vol. 17, No. 3, 2015, 78-82, ISSN 1335-4205.

[12] KRAJCOVIC, M., STEFANIK, A., DUliNA, L.: Logistics Processes and Systems Design Using Computer Simulation. Communications - Scientific Letters of the University of Zilina. vol. 18, No. 1A, 2016, 87-94, ISSN 1335-4205.

[13] RAKYTA, M., FUSKO, M., HALUSKA, M., GRZNAR, P.: 2016. Maintenance Support System for Reconfigurable Manufacturing Systems. Annals of DAAAM Proc. of the 26-th DAAAM Intern. symposium on intelligent manufacturing and automation, 11021108, ISBN 978-3-902734-07-5. 